\title{
CARACTERIZAÇÃO DO AMIDO DE ARARUTA ORGÂNICA E POTENCIAL PARA APLICAÇÃO TECNOLÓGICA EM ALIMENTOS
}

Characterization of organic arrowroot starch and potential for application in food Caracterización del almidón de araruta orgánico y potencial para aplicación en alimentos

Nayara Bonpan Ferreira Lima ${ }^{1}$, Leylane Barbosa Silva ${ }^{1}$, Mikaelly Veiga Borges $^{1}$, Raquel Rodrigues Neves ${ }^{1}$, Rosângela Vera ${ }^{1}$, Gislene Auxiliadora Ferreira ${ }^{1}$

1 Grupo de estudos em processados orgânicos, Engenharia de Alimentos, Universidade Federal de Goiás, Goiás, Brasil.

*Correspondência: Grupo de estudos em processados orgânicos, Universidade Federal de Goiás, Rodovia GoiâniaNova Veneza, km 0, s/n, Campus Samambaia, Goiânia, Goiás, Brasil. CEP:74690-900. e-mail: gepoa@ gmail.com

\section{RESUMO}

O amido de araruta possui potencial para aplicação em alimentos e gera produtos sem glúten. O objetivo deste trabalho foi estudar as propriedades do amido visando a sua aplicação tecnológica em alimentos. Os rizomas de araruta foram obtidos em plantação da Escola de Agronomia da Universidade Federal de Goiás. Para obter o amido os rizomas foram triturados, peneirados e secos. Foram realizadas análises de capacidade de formação de gel, atividade de água, acidez titulável, umidade, $\mathrm{pH}$, colorimetria, solubilidade em água e leite, índice de absorção em água, óleo e leite. A umidade $(9,49 \%)$ e Aw $(0,32)$ são esperados para o tipo de produto e estão dentro da legislação. $\mathrm{O}$ pH de 6,68 caracteriza os amidos nativos, a coloração é natural dos rizomas que geraram o amido. A solubilidade em leite foi maior do que em água e o índice de absorção foi maior em leite confirmando o potencial do amido aplicado em alimentos à base de leite como os panificados. $\mathrm{O}$ amido possui potencial para aplicação em alimentos e representa alternativa de alimentação para celíacos.

Palavras-chave: gel, absorção, rizomas.

\section{ABSTRACT}

Ararut starch has potential for application in food and generates products without gluten. The objective of this work was to study the properties of the starch for its technological application in food. Araruta rhizomes were obtained from the Agronomy School of the Federal University of Goiás. To obtain the starch the rhizomes were crushed, sieved and dried. Analyzes of gel formation capacity, water activity, titratable acidity, moisture, $\mathrm{pH}$, colorimetry, water and milk solubility, water, oil and milk absorption index were performed. Humidity (9.49\%) and Aw (0.32) are expected for the product type and are within the legislation. The pH of 6.68 characterizes the native starches, the natural coloration of the rhizomes that generated the starch. The solubility in milk was higher than in water and the absorption index was higher in milk confirming the potential of the starch applied in milk-based foods such as baked goods. The starch has potential for application in food and represents alternative food for celiacs.

Keywords: gel, absorption, rhizomes.

\section{RESUMEN}

El almidón de araruta tiene potencial para aplicación en alimentos y genera productos sin gluten. El objetivo de este trabajo fue estudiar las propiedades del almidón visando su aplicación tecnológica en alimentos. Los rizomas de araruta fueron obtenidos en plantación de la Escuela de Agronomía de la Universidad Federal de Goiás. Para obtener el almidón los rizomas fueron triturados, tamizados y secos. Se realizaron análisis de capacidad de formación de gel, actividad de agua, acidez titulable, humedad, $\mathrm{pH}$, colorimetría, solubilidad en agua y leche, índice de absorción en agua, aceite y leche. La humedad $(9,49 \%)$ y Aw $(0,32)$ se espera para el tipo de producto y están dentro de la legislación. El pH de 6,68 caracteriza los almidones nativos, la coloración es natural de los rizomas que generaron el almidón. La solubilidad 
en leche fue mayor que en agua y el índice de absorción fue mayor en leche, confirmando el potencial del almidón aplicado en alimentos a base de leche como los panificados. El almidón tiene potencial para la aplicación en alimentos y representa una alternativa de alimentación para celíacos.

Descriptores: gel, absorción, rizomas.

\section{INTRODUÇÃO}

A araruta (Maranta arundinacea L.) é uma planta herbácea de aproximadamente 1,2 metros de altura, perene e com rizomas longos, se desenvolve bem em solos úmidos, arenosos e profundos, com elevado teor de matéria orgânica. Seu amido é utilizado na indústria como espessante em alimentos, mas também representa uma excelente alternativa para substituição do trigo em produtos panificados, proporcionando alimentos sem glúten (Devide, 2013).

Para obtenção da fécula ou amido de araruta é necessária a trituração desta e posterior separação do amido da massa fibrosa através de peneiragem da massa. Após a separação do amido por decantação, este deve ser seco e depois triturado para homogeneização. O rendimento para obtenção do amido de araruta é de $16 \%$ (Nogueira et al., 2013).

$\mathrm{Na}$ indústria de alimentos, o amido é útil para se obter maior viscosidade, poder gelificante, adesão, tendência a retrogradação, que é devido à relação amilose/amilopectina, teor de proteína e relação de gordura além da estrutura, forma e tamanho dos grãos. Os níveis de lipídios no amido fixam a cor e manifestam aromas (Leonel et al., 2002).

Apesar de possuir características tecnológicas interessantes para a indústria alimentícia, devido ao volume de produção e custo final, a araruta foi substituída pela mandioca (Manihotesculenta Crantz) como matéria prima para obtenção de amido (Neves et al., 2005).

O potencial de mercado internacional da araruta é alto, devido ao elevado teor de amido. Por isso, o resgate do plantio dessa cultura pode significar um aumento de renda para a agricultura familiar (Souza et al, 2016).
Neste contexto, objetivou-se estudar as propriedades físico-químicas do amido de araruta, visando a aplicação na indústria de alimentos a fim de beneficiar consumidores celíacos e adeptos da alimentação orgânica.

\section{MATERIAIS E MÉTODOS}

Os rizomas de araruta orgânica foram plantados em área da Escola de Agronomia da Universidade Federal de Goiás.

Para a obtenção do amido de araruta inicialmente os rizomas foram lavados para retirar as sujidades, em seguida, foram cortados e colocados em liquidificador marca Brusque modelo 238, adicionando $600 \mathrm{~mL}$ de água para 500 gramas de araruta, sendo a quantidade total de $2 \mathrm{~kg}$. O conteúdo triturado foi coado com auxílio de um pano devidamente limpo. Para separar o polvilho, adicionaram-se $500 \mathrm{~mL}$ de água sobre o pano, mexendose bem a massa de modo a lavá-la para extração de todo polvilho. Recolheu-se o que foi coado em uma bacia. $\mathrm{O}$ leite de amido foi deixado em repouso por, aproximadamente, 2 horas em temperatura ambiente ( 25 ${ }^{\circ} \mathrm{C}$ ) para ocorrer a sedimentação do amido. Após a retirada do líquido sobrenadante, foi adicionado água na proporção de $500 \mathrm{~mL}$ por 2 vezes para a lavagem. Após as lavagens, o material foi deixado por 2 horas em repouso em temperatura ambiente. Em seguida, o sobrenadante foi descartado e o amido obtido foi exposto ao sol para secagem por, aproximadamente, 2 dias e depois, foi armazenado em sacos de polietileno.

A determinação de umidade foi feita por meio da perda de peso da amostra após o aquecimento direto em estufa a $130^{\circ} \mathrm{C}$, seguindo as normas estabelecidas pelo Instituto Adolfo Lutz (2008). Os valores foram expressos em porcentagem. Na determinação da acidez titulável, 
seguiram-se as indicações estabelecidas pelo Instituto Adolfo Lutz (2008) e os resultados foram expressos em $\mathrm{mL}$ de $\mathrm{NaOH}$. $\mathrm{O} \mathrm{pH}$ foi determinado em potenciômetro, modelo portátil DM pH-2 Hanna Instruments, com eletrodo inseridoemumasoluçãocontendo10gramas de amostra em $100 \mathrm{~mL}$ de água destilada segundo Instituto Adolf Lutz (2008).

A coloração do amido de araruta foi determinada por meio de espectrofotômetro da marca Minolta modelo CR 400 e as coordenadas ( $\mathrm{L}^{*}, \mathrm{a}^{*}$ e $\mathrm{b}^{*}$ ) foram lidas em amostras retiradas de diferentes pontos da superfície. Os valores de L* (luminosidade ou brilho) variam do preto (0) ao branco (100), os valores do croma $\mathrm{a}^{*}$ do verde(-60) ao vermelho $(+60)$ e os valores do croma $b^{*}$ do azul ao amarelo, de $-60 a+60$. A granulometria foi realizada em um vibrador de peneiras contendo inicialmente 100 gramas de amostra com peneiras de abertura 0,10mm, 0,15mm, 0,20mm e 0,30mm. Após o peneiramento, as frações retidas em cada peneira foram quantificadas por meio de pesagem. A metodologia utilizada foi granulometria por peneiramento de acordo com a NBR NM 248 (2003). Na análise de atividade de água, os valores foram determinados no equipamento analisador de atividade de água aqualab modelo cx-2.

A solubilidade em água foi determinada segundo metodologia de Okezie e Bello (1988). Uma suspensão com $25 \mathrm{~mL}$ de água e $0,5 \mathrm{~g}$ de amido (base seca) foi preparada em tubos de centrífuga com tampa. Os tubos foram agitados por 1 minuto em agitador PHOENIX, modelo AP 56 e, em seguida, centrifugados a $5300 \mathrm{rpm}$ por 20 minutos em centrífuga Eppendorf Centrifuge, modelo 5403. O líquido sobrenadante foi vertido cuidadosamente em placa de petri previamente tarada e levado à estufa para secagem. A solubilidade em água foi calculada pela relação entre o peso do resíduo seco do sobrenadante(resíduo de evaporação) e o peso seco da amostra conforme Fórmula 1:

$$
S A=\frac{\text { Resíduo de evaporação }(g)}{\text { Peso da amostra }} * 100
$$

A solubilidade em leite foi determinada segundo metodologia de Okezie e Bello(1988) porém com uma suspensão com $25 \mathrm{~mL}$ de leite e 0,5 g de amido (base seca). A solubilidade em leite foi calculada pela relação entre o peso do resíduo seco do sobrenadante (resíduo de evaporação) e o peso seco da amostra pela Fórmula 1.

A capacidade de formação de gel do amido foi determinada de acordo com a metodologia descrita por Coffmann e Garcia (1977). Dispersões de concentrações deamostravariandoentre $8 \%$ a20\% de amido em $20 \mathrm{~mL}$ de água foram preparadas em tubos de ensaio de $50 \mathrm{~mL}$.Emseguida, as dispersões foram aquecidas a $90^{\circ} \mathrm{C}$ por $30 \mathrm{~min}$, resfriadas à temperatura ambiente e refrigeradas a $4^{\circ} \mathrm{C}$ por 2 horas. Após, os tubos foram invertidos e analisados em relação à formação de gel. Todas as análises foram realizadas em quadruplicata.

O índice de absorção de água foi determinado segundo metodologia de Okezie e Bello (1988). Uma suspensão com $25 \mathrm{~mL}$ de água e $0,5 \mathrm{~g}$ de amido foi preparada em tubos de centrífuga com tampa. Os tubos foram agitados durante 1 minuto, em agitador de tubos e, em seguida, centrifugados a $5300 \mathrm{rpm}$, por 20 minutos, em centrífuga Eppendorf Centrifuge, modelo 5403. O líquido sobrenadante foi escorrido, e o material que sobrou foi pesado. A diferença entre a massa da amostra, antes e após a absorção de água, representou a quantidade de água absorvida. O índice de absorção de água foi calculado de acordo com a Fórmula 2:

$$
I A A=\frac{\text { Água absorvida pela amostra }(g)}{\text { M assa da amostra }(g)}
$$

Determinou-se o índice de absorção de leite segundo a metodologia descrita anteriormente, centrifugando a solução, preparada com $25 \mathrm{~mL}$ de leite e 
0,5g de amostra, a $3000 \mathrm{rpm}$, por 20 minutos, a $4{ }^{\circ} \mathrm{C}$. O índice de absorção de leite foi calculado de acordo com a Fórmula 3:

$$
I A L=\frac{\text { Leite absorvida pela amostra }(g)}{\text { M assa da amostra }(g)}
$$

O índice de absorção de óleo foi determinado segundo a metodologia descrita para água, utilizando-se $25 \mathrm{~mL}$ de óleo de soja para o preparo da solução. O índice de absorção de óleo foi calculado de acordo com a Fórmula 4:

$$
I A O=\frac{\text { Óleo absorvida pela amostra }(g)}{\text { M assa da amostra }(g)}
$$

Os dados obtidos foram submetidos a cálculos de média aritmética, coeficiente de variação e desvio padrão, calculados através do software Microsoft Excel 2007.

\section{RESULTADOS E DISCUSSÃO}

Os resultados obtidos nas análises realizadas no amido de araruta encontram-se na Tabela 1. A umidade e a atividade de água da farinha de araruta foram de $9,49 \%$ e 0,32 , respectivamente. Para a obtenção do amido de araruta ocorre uma etapa de secagem o que contribui para a redução da umidade e atividade de água do produto final. $\mathrm{O}$ teor de umidade encontrado está de acordo com os valores de referência obtidos da literatura de Ferrari et al. (2005), onde os valores relatados foram de $10,49 \%$ e $9,85 \%$. Segundo a Resolução - CNNPA n 12, de 1978 da Agência Nacional de Vigilância Sanitária (Brasil, 1978), o amido de araruta pode conter no máximo $14 \%$ de umidade, desta forma, o resultado encontrado neste trabalho está dentro dos padrões estabelecidos.

Com relação à granulometria, 70\% do amido que foi submetido ao teste ficou retido na peneira de abertura de $0,15 \mathrm{~mm}$, sendo possível classificá-lo como fino. A granulometria do amido é uma característica importante, pois interfere diretamente na sua aplicação tecnológica e atributos de qualidade, como o aspecto do produto final, afetando o tempo de mistura da massa em produtos panificados e absorção de água na massa (Lopes e Demiate, 2015).

$\mathrm{O}$ resultado encontrado para o $\mathrm{pH}$ foi de 6,68 indicando um bom estado de maturação da araruta. Esse parâmetro influencia indiretamente em sua qualidade tecnológica, sendo que a maior parte dos amidos nativos, ou seja, que não sofreram modificações, possuem $\mathrm{pH}$ próximo a neutralidade. $\mathrm{O} \mathrm{pH}$ acima de 6,0 possibilita a ação de enzimas que degradam o amido (Cunha, 2016) .

Encontrou-se para a acidez titulável o valor de 0,71 unidades. Segundo Cunha (2016), como estabilizante de emulsões é necessário que o amido tenha maior resistência à acidez, logo o amido não seria indicada para este fim. $\mathrm{O}$ volume gasto na análise da acidez titulável foi de $2,25 \mathrm{~mL}$ por $100 \mathrm{~g}$ da amostra, o que está dentro do padrão, considerando a Resolução CNNPA n ${ }^{\circ}$ 12, de 1978 da ANVISA, em que o amido de araruta deve estar entre $2 \mathrm{~mL}$ e $5 \mathrm{~mL}$ para $100 \mathrm{~g}$ de amostra (Brasil, 1978).

Os valores encontrados na determinação de cor foram: $\mathrm{L}(92,6), \mathrm{a}^{*}(1,47)$ e $\mathrm{b}^{*}(12,71)$. Valores mais altos de L (próximos de 100) indicam farinha de cor mais branca, valores de $\mathrm{a}^{*} \mathrm{e} \mathrm{b}^{*}$ maiores caracterizam a cor vermelha e amarela, respectivamente, logo o amido analisado possui cor mais clara tendendo ao branco sem intensificação das cores vermelhas e amarelas, porém com pequenas nuances amareladas. A cor é coerente pois a araruta possui cor clara, logo origina um amido de cor característica. A cor de um produto é muito importante pois é o primeiro fator avaliado na compra pelo consumidor, seja do amido in natura ou dos produtos 
formulados tendo como base o amido de araruta. A cor do amido irá influenciar diretamente em produtos panificados, mas em uso como espessante não influenciará de forma significativa no produto final pois a cor do produto predominante irá sobressair ( Agustinha, 2013).

Os coeficientes de variação das análises de umidade, atividade de água, pH, acidez titulável e colorimetria tiveram valores baixos indicando que os dados estão mais concentrados em torno do valor de média e que os dados obtidos nas análises são homogêneos. Sendo valores abaixo de $10 \%$ representam a exatidão dos dados experimentais obtidos. Os desvios padrões calculados indicam a pequena dispersão dos dados de cada análise em relação à sua média (Bussab e Morettin, 2017).

Tabela 1. Características fisicas e químicas de amido extraído de araruta orgânica.

\begin{tabular}{llllllll}
\hline & $\begin{array}{l}\text { Umidade } \\
(\%)\end{array}$ & $\begin{array}{l}\text { Atividade } \\
\text { de água }\end{array}$ & $\mathbf{p H}$ & $\begin{array}{l}\text { Acidez } \\
\text { titulável }\end{array}$ & $\mathbf{L}$ & $\mathbf{a}^{*}$ & $\mathbf{b}^{*}$ \\
\hline & 9,50 & 0,330 & 6,68 & 0,72 & 92,7 & 1,20 & 12,71 \\
& 9,48 & 0,320 & 6,68 & 0,71 & 92,6 & 1,20 & 12,71 \\
& 9,49 & 0,330 & 6,68 & 0,71 & 92,7 & 1,22 & 12,72 \\
Média & 9,49 & 0,327 & 6,68 & 0,71 & 92,67 & 1,20 & 12,71 \\
Coeficiente & de & & & & & & \\
variação (\%) & 0,10 & 1,76 & 0 & 0,81 & 0,062 & 0,02 & 0,045 \\
Desvio padrão & 0,01 & $5,77 \times 10^{-3}$ & 0 & $5,77 \times 10^{-3}$ & 0,058 & 1,66 & $5,77 \times 10^{-3}$ \\
\hline
\end{tabular}

Tabela 2. Índice de solubilidade em amido extraído de araruta.

\begin{tabular}{llll}
\hline & $\begin{array}{l}\text { Índice de absorção } \\
\text { em água }(\mathbf{g ~ g}-1)\end{array}$ & $\begin{array}{l}\text { Índice de absorção } \\
\text { em óleo }(\mathbf{g ~ g - 1 )}\end{array}$ & $\begin{array}{l}\text { Índice de absorção } \\
\text { em leite ( g g-1) }\end{array}$ \\
\hline & 0,8385 & 1,05 & 1,49 \\
& 0,7950 & 1,09 & 1,61 \\
& 0,8327 & 1,14 & 1,39 \\
Média & 0,8221 & 1,09 & 1,50 \\
$\begin{array}{l}\text { Coeficiente } \\
\text { de variação }\end{array}$ & & \\
(\%) & 2,87 & & \\
Desvio & & 4,14 & 7,34 \\
padrão & 0,0236 & & 0,11 \\
\hline
\end{tabular}


Tabela 3. Solubilidade em amido extraído de araruta.

\begin{tabular}{lll}
\hline & $\begin{array}{l}\text { Solubilidade } \\
\text { em água (\%) }\end{array}$ & $\begin{array}{l}\text { Solubilidade } \\
\text { em leite (\%) }\end{array}$ \\
\hline & 8,8386 & 585,4174 \\
& 2,0379 & 554,3992 \\
& 1,8297 & 471,4541 \\
& 1,8069 & 542,0278 \\
Média & 3,6283 & 534,0746 \\
Coeficiente de & 103,3817 & 9,0783 \\
variação (\%) & \\
Desvio padrão & 3,7510 & 48,4849 \\
\hline
\end{tabular}

Tabela 4. Concentração de amido e formação de gel

\begin{tabular}{ll}
\hline $\begin{array}{l}\text { Concentração do } \\
\text { amido }\end{array}$ & $\begin{array}{l}\text { Capacidade de } \\
\text { formação do gel }\end{array}$ \\
\hline $8 \%$ & + \\
$10 \%$ & + \\
$12 \%$ & ++ \\
$14 \%$ & ++ \\
$16 \%$ & ++ \\
$18 \%$ & + \\
\hline $20 \%$ & ++ \\
\hline
\end{tabular}

1,05 a $1,14 \mathrm{~g} \mathrm{~g}^{-1}$ e está relacionado com a capacidade

De a acordo com a Tabela 2 índice de absorção de água variou de 0,79 a $0,83 \mathrm{~g} \mathrm{~g}^{-1}$, a absorção de água está relacionada à quantidade de água que pode ser absorvida pelo amido e depende da quantidade de grupos hidrofílicos que estão presentes na amostra, além de sua propriedade higroscópica que facilita também a absorção de água. A alta absorção de água no amido é desejável para produtos com elevada quantidade de água e tem-se o objetivo de aumentar a viscosidade do produto ( Filli e Nkama, 2007).

O índice de absorção em leite variou de 1,39 a 1,61 $\mathrm{g} \mathrm{g}^{-1}$ e mostra que os componentes do amido estudado tem maior interação com as moléculas do leite, essa característica é desejável quando o produto elaborado tem como base o leite o que auxilia na homogeneização dos componentes e diminui a probabilidade de ocorrer sinérese (Becker et al., 2014).

O índice de absorção em óleo variou de do amido de segurar óleo em suas estruturas além da presença de grupos hidrofóbicos que também contribuem (Ravi e Suselamma, 2005).

A partir da Tabela 3 vemos que a solubilidade em água das amostras analisadas ficaram entre 1,80\% a $8,83 \%$ e a solubilidade em leite teve valores entre $471 \%$ e $585 \%$, o que indica que as interações entre o amido e o leite são bem maiores em relação à água. A solubilidade em água obtida são valores relativamente baixos devido ao teor de amilose do amido, pois a amilose é melhor dissolvida quando há o aquecimento, o que não ocorreu durante a análise. $\mathrm{O}$ aumento da solubilidade é mais eficiente quando ocorre a quebra das cadeias de amilose (Zeoula et al., 1999).

A partir do estudo realizado por Rodrigues (2014) foram encontrados valores de solubilidade em água entre $0,15 \%$ e $22,1 \%$ o que está dentro da faixa 
de valores encontrada neste trabalho, porém com

um valor máximo de $22,1 \%$ devido ao

aquecimento que ocorreu no estudo.

O resultado do coeficiente de variação da análise de solubilidade em água foi o maior, indicando a existência de dados heterogêneos e a possível inexatidão dos dados obtidos experimentalmente.

A gelatinização do amido é caracterizada pelo aumento irreversível dos grânulos de amido quando estes entram em contato com a água e temperatura. Observase a partir da tabela 4 que quanto maior a concentração de amido de araruta maior foi a capacidade de formação de gel. Segundo Costa et al (2014), os rizomas de araruta contém cerca de $20 \%$ de amido onde $20 \%$ a $30 \%$ deste conteúdo é composto por amilose. A grande quantidade de amilose presente diminui a energia necessária para início da gelatinização, assim amidos que possuem maior quantidade de amilose apresentam menos regiões cristalinas e, consequentemente, menores temperaturas de gelatinização (Denardin e Silva, 2009).

\section{CONCLUSÃO}

A partir dos estudos realizados pode-se concluir que o amido de araruta possui propriedades importantes para ser utilizado na indústria alimentícia, principalmente em produtos panificados e à base de leite, representando uma alternativa de alimentação para consumidores celíacos ou adeptos da alimentação orgânica.

\section{AGRADECIMENTO}

Agradecemos às nossas orientadoras, Gislene Auxiliadora e Rosângela Vera, por terem contribuído com a realização deste trabalho e nos incentivar a sermos melhores a cada dia. Agradecemos também à Jessyca Santos Silva por ter nos auxiliado na execução do trabalho.
Todos os autores declararam não haver qualquer potencial conflito de interesses referente a este artigo.

\section{REFERÊNCIAS}

AGUSTINHA, P. L. Análises Laboratoriais para o Controle de Qualidade da Farinha de Trigo e Garantia da Qualidade na Produção de Alimentos. Palotina, PR. Trabalho de conclusão de curso (Curso Superior Tecnologia em Biotecnologia). Universidade Federal do Paraná - UFPR; 2013.

ASSOCIAÇÃO BRASILEIRA DE NORMAS TÉCNICAS. 2003. NBR NM 248: Agregados -

Determinação da composição granulométrica. Rio de Janeiro, 01 set., p. 6.

BECKER, F.S.; DAMIANI, C.; MELO, A.A.M.; BORGES, P.R.S. Incorporation of buriti endocarp flour in gluten-free whole cookies as potential source of dietary fiber. Plant Foods for Human Nutrition. v. 69, n. 4 , p. 344-350, 2014.

BRASIL. Resolução - CNNPA n. 12, de 24 de jul. de 1978. Agência Nacional de Vigilância Sanitária. Disponível em: $<$ https://www.anvisa.gov.br/anvisalegis/resol/12_ 78.htm> . Acesso em: 26/03/2018.

BUSSAB, W. O.; MORETTIN, P. A.Estatística

Básica. 9. ed. São Paulo, Saraiva Uni; 2017.

COFFMANN, C. W.; GARCIA, V. V. Functional properties and amino acid content of a protein isolate from mung bean flour. Journal of Food Technology. v. 12 , n. 5 , p. 473- 484, 1977.

COSTA, R.A.S.; VELOSO, C.M.; FONTAN, R.C.I.; BONOMO, R.C.F. Composição centesimal da fécula de araruta da variedade comum. In. Congresso Brasileiro de Química, Natal, Anais. CBQ, v. 54, p. 15, 2014.

CUNHA, A. L. Caracterização do amido de araruta tipos seta e redonda, visando utilização na indústria de alimentos. Lavras, MG. Dissertação de Mestrado. Universidade Federal de Lavras - UFLA; 2016.

DENARDIN, C. C.; SILVA, L. P. Estrutura dos grânulos de amido e sua relação com propriedades físico-químicas. Ciência Rural. v. 39, n. 3, p.945-954, 2009.

DEVIDE, A. C. P. Culturas anuais para sistemas 
agroflorestais com guanandi em várzea e terraço fluvial. Seropédica, RJ. Tese de Doutorado. Universidade Federal Rural do Rio de Janeiro UFRRJ; 2013.

FERRARI, T. B.; LEONEL, M.; SARMENTO, S. B. $\mathrm{S}$. Características dos rizomas e do amido de Araruta (Maranta arundinacea) em diferentes estádios de desenvolvimento da planta. Brazilian Journal and Food Technology. v. 8, n. 2, p. 93-98, 2005.

FILLI, K. B.; NKAMA, I. Hydratation properties of extruded fura from millet and legumes. British Food Journal. v. 109, n. 1, p. 68-80, 2007.

INSTITUTO ADOLFO LUTZ. Normas Analíticas do Instituto Adolfo Lutz: Métodos químicos e físicos para análise de alimentos. 4. ed., São Paulo, IMESP; 2008.

LEONEL, M.; CEREDA, M. P.; SARMENTO, S.

Processamento de Araruta (Maranta arundinacea) para Extração e Caracterização da Fração Amilácea. Brazilian Journal Food Technology, v.5, n.1, p.151155, 2002.

LOPES, R. B.; DEMIATE, I. M. Avaliação granulométrica de frações constituintes de farinhas de trigo tipo 1 obtidas da moagem industrial de cultivares disponíveis no mercado brasileiro. Revista Brasileira de Tecnologia Agroindustrial Ponta Grossa. v. 9, n. 1, p. 1786-1796, 2015.

NEVES, M. C. P.; COELHO, I. S.; ALMEIDA, D.L. 2005. Araruta: resgate de um cultivo tradicional. Disponível em: http://www.infoteca.cnptia.embrapa.br/infoteca/handl e/doc/625391. Acesso em: 15/07/2018.

NOGUEIRA, T. Y. K.; PEREIRA, A. D.; FAKHOURI, F. M. Extração e caracterização do amido de araruta. In. Encontro de Ensino, Pesquisa eExtensão, 8, Dourados, Anais, ENEPEX, v. 388, p. $1-15,2013$.

OKEZIE, B.O.; BELLO, A.E. Physicochemical and functional properties of winged bean flour and isolate compared with soy isolate. Journal of Food Sciences. v. 53, n. 2, p.450-455, 1988.

RAVI, R.; SUSELAMMA, N. S. Simultaneous optimization of a multi-response system by desirability function analysis of boondi making: a case study. Journal of Food Science. v. 70, n. 8, p. 539547, 2005.
RODRIGUES, L. B. O. Estudos reológicos e de textura dos géis de amido de araruta (Maranta arundinaceae L.) e dos géis adicionados de sacarose e concentrado protéico de soro. Itapetinga, BA. Dissertação de Mestrado. Universidade Estadual do Sudoeste da Bahia - UESB; 2014.

SOUZA, D. C.; SILVA, L. L.; RESENDE, L. V.;COSTA, P. A.; GUERRA, T.S.; GONÇALVES, W. M.; PEREIRA, T. A.R. Conservação pós-colheita de araruta em função da temperatura de armazenamento. Magistra, v. 28, n. 3/4, p.403-410, 2016.

ZEOULA, L. M.; MARTINS, A.S.; PRADO, I. N.; ALCALDE, C. R.; BRANCO, A.F.; SANTOS, G. T. Solubilidade e Degradabilidade Ruminal do Amido de Diferentes Alimentos. Revista Brasileira de Zootecnia, v. 28, n. 5, p.898-905, 1999. 